Adrian W. Gelb Mв CH B, Gary K. Steinberg MD PH D, Arthur M. Lam MD, Pirjo H. Manninen MD, Sydney J. Peerless MD, Aziz Rassi-Neto MD

\title{
The effects of a prophylactic bolus of lidocaine in focal cerebral ischaemia
}

In order to determine the cerebral protective effects of an intravenous bolus of $5 \mathrm{mg} \cdot \mathrm{kg}^{-1}$ of lidocaine, the left middle cerebrat artery (MCA) was transorbitally occluded in 19 cats. Ten animals received the lidocaine bolus and nine a similar volume of saline immediately before MCA acclusion. Somatosensory evoked potentials (SEP) were recorded before and after the tidocaine bolus as well as continually after MCA acclusion. After six hours of vessel occlusion and without reperfusion, the animals were sacrificed and the brains fixed for histology. Prior to MCA occlusion, lidocaine caused a statistically significant ( $p$ $<0.01)$ reduction in the amplitude of the major cortical component of the SEP $(10 \pm 1.2 \mu \mathrm{V} v s .0 \pm 1.3 \mu \mathrm{V})$. Latency was unchanged. In the lidocaine group, SEP's persisted in 40 per cent immediately following occlusion whereas they disappeared in all of the control animals $(p<0.05)$. Gradual recovery occurred in both groups and there were no differences at the end of the experiment although the umplitudes tended to be greater in the lidocaine group. There were no statistically significant differences in the histological size or severity of the infarcts between the groups. Although infarct size was not reduced, transient sparing of the SEP suggests that further studies of lidocaine by continuous infusion in models of temporary focal cerebral ischaemia may be warranted.

\section{Key words}

ANAESTHETICS, LOCAL: lidocaine; BRAIN: ischaemia, evoked potentials.

From the Departments of Anaesthesia and Clinical Neurological Sciences, University Hospital, University of Western Ontario, London, Ontario.

Address correspondence to: Dr. A. W. Gelb, Department of Anaesthesia, University Hospital, P.O. Box 5339, Station "A," London, Ontario, N6A 5A5.

Supported by the Heart and Stroke Foundation of Ontario Grant No: 3-20.
Lidocaine hydrochloride has been shown by neurochemical and electrophysiological criteria to have effects which might protect against cerebral ischaemia. ${ }^{1-3}$ Astrup, using massive doses of lidocaine $\left(160 \mathrm{mg} \cdot \mathrm{kg}^{-1}\right)$, demonstrated a marked reduction in cerebral metabolic rate and a prolongation of the tolerable limit of global ischaemia as measured by cellular potassium efflux.$^{1,2}$ Using similar large doses, we were unable to show a protective effect in experimental focal cerebral ischaemia, perhaps as a consequence of the haemodynamic effects of such large doses. ${ }^{4}$ More recently, Evans has shown that lidocaine in lower doses (5 mg $\mathrm{kg}^{-1}$ ) preserved the somatosensoryevoked potential (SEP) in cerebral ischaemia created by air embolism. ${ }^{3}$ However, they only assessed the animals for two hours. We have re-evaluated this lower dose of lidocaine in a feline model of focal cerebral ischaemia created by middle cerebral artery (MCA) occlusion. SEP's were monitored for six hours and the extent of brain injury characterized histologically.

\section{Methods}

After approval by the Council on Animal Care at our institution, 19 adult cats, each weighing between 2,5 and $4 \mathrm{~kg}$, were studied. The study was divided into two phases. In the first phase, a tourniquet was implanted around the left MCA and the SEP response to an intravenous bolus of $5 \mathrm{mg} \cdot \mathrm{kg}^{-1}$ lidocaine was evaluated. In the second phase, the protective effect of a bolus of lidocaine was evaluated when the toumiquet was tightened. The anaesthetic technique and the method of monitoring the SEP were identical in both phases.

\section{Phase I}

Each animal was sedated with ketamine $\mathrm{HCl}\left(30 \mathrm{mg} \cdot \mathrm{kg}^{-1}\right.$ intraperitoneally) and atropine sulphate $(0.2 \mathrm{mg}$ intraperitoneally), intubated, paralyzed with gallamine triethiodide $\left(0.3 \mathrm{mg} \cdot \mathrm{kg}^{-1}\right)$ and artificially ventilated with air and oxygen ( $\mathrm{FIO}_{2}$ 0.6). Anaesthesia was maintained with halothane ( $0.75-1.25$ per cent inspired) adjusted to keep the blood pressure constant at approximately $120 / 80$. A cephalic venous catheter was inserted and 0.9 per cent saline infused at $4 \mathrm{ml} \cdot \mathrm{hr}^{-1}$. A femoral arterial cut-down 
catheter was placed for continuous measurement of blood pressure and for artcrial blood gas sampling. A capnograph was used to monitor end-expired $\mathrm{CO}_{2}\left(\mathrm{ETCO}_{2}\right)$ which was kept between 30 and $35 \mathrm{mmHg}$. Arterial blood gases were drawn to check the adequacy of oxygenation, confirm the accuracy of end-expired $\mathrm{CO}_{2}$ and to measure $\mathrm{pH}$. Base deficit was corrected when necessary with intravenous sodium bicarbonate. Body temperature was measured with a rectal probe and kept near $37.5^{\circ} \mathrm{C}$ with a warming blanket.

The head was immahilized in the sphinx position using skull pins and the left proximal MCA exposed transorbitally as previously described. ${ }^{5}$ A micro-toumiquet was placed around the artery but was not tightened. Bilateral SEP's were recorded before and after implantation to verify that the surgical procedure did not affect the evoked potentials.

Bilateral SEP's were recorded from silver/silver chloride cup electrodes positioned over the coronal sutures $1 \mathrm{~cm}$ lateral to the mid-line and attached with collodion. The reference electrode was placed on the glabella. Impedence was maintained at less than 3000 ohms. Paired stimulating needle electrodes were placed subdermally over the median nerve proximal to the transverse carpal ligament bilaterally. Square wave stimuli of $0.2 \mathrm{msec}$ duration and $10 \mathrm{~mA}$ were delivered at a rate of $4.1 / \mathrm{sec}$ to each median nerve while evoked potentials were recorded from the contralateral scalp. Visible twitching of the appropriate paw was observed in all cases before muscle relaxants were given. The SEP's were recorded with a Nicolet CA 1000 signal averager. The band pass filtre was set between 5 and $3000 \mathrm{~Hz}$, with a recording duration of $20 \mathrm{msec}$ and sensitivity of 50 microvolts. Two hundred and fifty six responses were averaged and stored for subsequent analysis. To ensure reproducibility, each averaged SEP was recorded in duplicate.

Latencies of the major positive $(\mathrm{P})$ and negative $(\mathrm{N})$ cortical deflections were determined. The amplitude of the primary cortical potential was measured from the peak of the major positive deflection to the trough of the major negative deflection.

To determinc the effect of a $5 \mathrm{mg} \cdot \mathrm{kg}^{-1}$ lidocaine bolus on the normal SEP, the SEP was recorded before and after a lidocaine bolus.

\section{Phase 2}

Following tourniquet implantation, the animals were observed during one-week recovery, and only studied in the second phase if there were no neumlogical deficits. Each cat was again anaesthetized as outlined above. The tourniquet was exposed and base-line SEP's recorded. Ten cats received a single slow intravenous bolus of lidocaine $\left(5 \mathrm{mg} \cdot \mathrm{kg}^{-1}\right)$ ten minutes before occlusion and nine animals received a similar volume of 0.9 pcr cent saline. The left MCA was then occluded by tightening the tourniquet. SEP's were recorded every five minutes after occlusion for thirty minutes and then at thirty-minute intervals over the next five and a half hours. Halothane anaesthesia (0.75-1.25 per cent) was maintained over this entire period.

Six hours after MCA occlusion and without releasing the toumiquet, each animal was killed with pentobarbitone (20 $\mathrm{mg} \cdot \mathrm{kg}^{-1}$ ). Perfusion fixution was performed through a left ventriculostomy using $500 \mathrm{ml}$ of isotonic saline followed by $500 \mathrm{ml}$ of 10 per cent phosphate buffered formalin. The brains were fixed in situ for a minimum of one week. Then they were removed and immersed in formalin for one to three months before processing. The left MCA was inspected to verify occlusion.

An eight micron coronal section $3 \mathrm{~mm}$ posterior to the temporal lobe tip, through the optic chiasm, was processed and stained with hematoxylan and eosin. This section includes part of the somatosensory cortex. Without knowledge of the treatment group or the postocclusion SEP's, the left hemisphere was microscopically examined and the extent of grey matter injury was recorded on an $8 \times 10$ photograph of the section. A standardized, previously described, histological scoring system was used. ${ }^{6}$ Briefly, the brain was graded as normal, or as showing evidence of mild (Grade 1), moderate (Grade II), or severe (Grade III) ischaemic injury. The area of each grade was summed and expressed as a percentage of the total hemispheric grey matter.

Statistical analysis was performed using the Chi Square test and unpaired $t$-test. A $p$ value $<0.05$ was regarded as statistically significant.

\section{Results}

There were no statistically significant differences in the blood pressure, heart rate, ETCO $\mathrm{Cr}_{2}$ inspired halothane concentration used between the two groups during the course of the study.

There were no significant differences in latency or amplitude of the left or right hemisphere SEP's before tourniquet implantation compared with the post-implantation values. During the acute experiment, the SEP's prior to arterial occlusion were similar to those recorded during the implantation procedure and there were no differences between the groups. A cortical potential with a major positive $(P)$ and negative $(N)$ deflection was always present. Other smaller far-field positive potentials usually preceded the major cortical potential but these were not consistently observed in all cats.

Lidocaine infusion prior to the occlusion of the MCA caused a small but statistically significant $(\mathrm{p}<0.01)$ reduction of the amplitude of the major cortical component with no change in latency (Table I). 


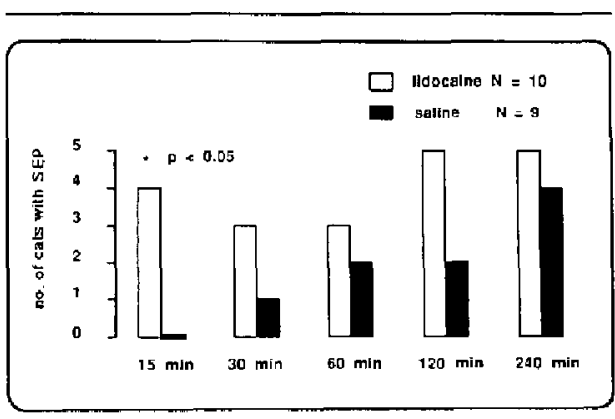

FIGURE The aumber of animals with preservation of the SEP after sniddle cerebral artery occlusion is shown for each time period. A statistically significant differenee between the lidocaine and saline animals was found at 15 minutes after occlusion.

In the lidocaine group, SEP's persisted in 40 per cent of the cats immediately following occlusion of the artery whereas in all of the control animals SEP's disappeared ( $\mathrm{p}$ $<0.05$ ) (Figure). However, gradual recovery subsequently occurred in both groups and there were no differences at the end of the experiment. Five lidocaine and four control animals had detectable SEP's at the end

TABLE 1 Effect of lidocaine $5 \mathrm{mg} \cdot \mathrm{kg}^{-1}$ on SEP (mean $\pm \mathrm{SEM}$ )

\begin{tabular}{|c|c|c|c|c|}
\hline & \multicolumn{2}{|l|}{ Before } & \multicolumn{2}{|c|}{ After lidocaine } \\
\hline & $p$ & $N$ & $P$ & $N$ \\
\hline $\begin{array}{l}\text { Latcncy } \\
\text { (msec) }\end{array}$ & $9.4 \pm 0.2$ & $13.5 \pm 0.2$ & $9.6 \pm 0.3$ & $13.7 \pm 0.5$ \\
\hline $\begin{array}{l}\text { Amplitude } \\
\text { ( } \mu \mathrm{V})\end{array}$ & \multicolumn{2}{|c|}{$10 \pm 1.2$} & \multicolumn{2}{|c|}{$6.0 \pm 1.3^{*}$} \\
\hline
\end{tabular}

TABLE II Left hemisphere SEP (mean + SEM) before and after occlusion

\begin{tabular}{|c|c|c|c|c|}
\hline & \multicolumn{2}{|c|}{ Lidocaine $(n=\{0\}$} & \multicolumn{2}{|l|}{ Soline $(n=9)$} \\
\hline & $\boldsymbol{P}$ & $N$ & $P$ & $N$ \\
\hline \multicolumn{5}{|c|}{ Preacclusion } \\
\hline $\begin{array}{l}\text { Latency } \\
\text { (msec) }\end{array}$ & $9.5 \pm 0.2$ & $13.5 \pm 0.2$ & $10.0 \pm 10.0$ & $13.6 \pm 0.2$ \\
\hline $\begin{array}{l}\text { Amplitude } \\
(\mu \mathrm{V})\end{array}$ & \multicolumn{2}{|c|}{$9.2 \pm 1.1$} & \multicolumn{2}{|c|}{$8.9 \pm 1.7$} \\
\hline \multicolumn{5}{|c|}{ With recovery" } \\
\hline $\begin{array}{l}\text { Latency } \\
\text { (msec) }\end{array}$ & $8.8 \pm 0.4$ & $12.9 \pm 0.5$ & $9.0 \pm 0.3$ & $12.1 \pm 0.5$ \\
\hline $\begin{array}{l}\text { Amplitude } \\
(\mu V)\end{array}$ & \multicolumn{2}{|c|}{$5.2 \pm 0.9$} & \multicolumn{2}{|c|}{$3.4 \pm 0.2$} \\
\hline
\end{tabular}

${ }^{*}$ Lidocaine $n=5$, saline $n=4$.
TABLE III Recovery SEP as percentage of preacclusion SEP (mean \pm SEM)

\begin{tabular}{|c|c|c|}
\hline Lidocaine & \multicolumn{2}{|c|}{ Saline } \\
\hline \multicolumn{3}{|c|}{ Percenage of pre-lidocaine SEP } \\
\hline \multicolumn{2}{|c|}{$63.5 \pm 14.8$} & $6 \pm 6.5$ \\
\hline \multicolumn{3}{|c|}{ Percentage of post-lidocaine SEP } \\
\hline \multicolumn{2}{|c|}{$78.6 \pm 17.0$} & $6 \pm 6.5$ \\
\hline \multicolumn{3}{|c|}{ TABLE IV Area of ischnemic neuronal damage (mean \pm SEM) } \\
\hline Grade & Saline & Lidocaine $5 \mathrm{mg} \cdot \mathrm{kg}^{-\mathrm{s}}$ \\
\hline Mild & $26.7 \pm 4.1$ & $29.4 \pm 4.9$ \\
\hline Moderate & $21.4 \pm 5.7$ & $15.0=4.9$ \\
\hline Severe & $8.6 \pm 2.8$ & $7.5 \pm 2.4$ \\
\hline
\end{tabular}

Area is expressed as a por cent of cortical grcy matter.

of the study while five in each group had none discemible. In animals that exhibited some recovery of the SEP, no differences in amplitude or latency could be demonstrated between the two groups although the amplitude tended to be higher in the lidocaine group compared with the saline group (Table II). Expressing the armplitude after recovery as a percentage of the baseline values similarly yielded no significant differences between the two groups (63.5 \pm 14.8 per cent for lidocaine group vs $61.6 \pm 6.5$ per cent for saline group) (Table III). If the amplitudes following lidocaine infusion were used as baseline values, the percentage recovery was higher in the lidocaine group compared with the saline group $(78.6 \pm 17.0$ vs $61.6 \pm$ 6.5 per cent).

The results of the histological analysis are shown in Table IV. There were no statistically significant differences in the size or the severity of the infarcts between the groups.

\section{Discussion}

The major finding of this study was that a single bolus of 5 $\mathrm{mg} \cdot \mathrm{kg}^{-1}$ of lidocaine produced transienc ( $<30 \mathrm{~min}$ ) but statistically significant preservation of the SEP after middle cerebral artery occlusion. However, this beneficial effect was not sustained and did not result in an ameliotation of the histological extent of the the ischaemic lesion after six hours of arterial occlusion.

Lidocaine hydrochloride is commonly used as a local anaesthetic and as a cardiac anti-arrhythmic. Cerebral metabolic and neurochemical studies have indicated that lidocaine may also protect cerebral tissue during periods of global ischaemia. ${ }^{1,2}$ Potassium efflux, which has been shown to occur from cortical neurons during ischaemia, was delayed by massive doses $\left(160 \mathrm{mg} \cdot \mathrm{kg}^{-1}\right)$ of intravenous lidocaine. ${ }^{7}$ This dose of lidocaine also flattened the EEG and reduced oxygen and glucose consumption. 
However, the haemodynamic effects were such that the studies were done with the dogs on cardiopulmonary bypass. In vitro studies utilizing a vagus nerve preparation have shown that during periods of glucose lack the addition of lidocaine decreased axonal permeability to potassium and sodium ions. ${ }^{8}$ Astrup has speculated that lidocaine, by inhibiting electrocortical synaptic activity and by stabilizing membranes reduces cerebral energy expenditure and therefore delays the onset of irreversible structural damage. ${ }^{9}$ Lidocaine also has antithrombic properties which may help maintain blood flow through an ischaemic area. ${ }^{10}$

Somatosensory evoked potentials are commonly employed to monitor cerebral function during neurosurgery." A good comelation has been demonstrated between abolition of the SEP and a reduction in local cerebral blood flow to below $15 \mathrm{ml} \cdot 100 \mathrm{~g}^{-1} \cdot \mathrm{min}^{-1} .12,13$ In the present study, the preservation of the SEP in the lidocaine group immediately after occlusion and the tendency for the amplitude to be greater than the saline group are all interpreted as indicating that lidocaine maintained a better balance between energy delivery and demand. Indeed, such an assumption underlies the clinical utility of SEP's and has also been used experimentally by others ${ }^{3,14-17}$

Evans et al. recently reported that neurological function, as assessed by somatosensory evoked potentials, was substantially preserved following cerebral air embolism in the animals that received a single prophylactic dose of $5 \mathrm{mg} \cdot \mathrm{kg}^{-1}$ of lidocaine. ${ }^{3}$ Although our study shows a transient ( $<30 \mathrm{~min}$ ) protective effect, there was no sustained protection when assessed by both the SEP measurements and histology. The differences in results may be explained by differences in the animal models uscd as well as the method of analysis of SEPs. Cerebral air embolism in cats only transiently interrupts flow through small cerebral arteries and reperfusion occurs usually within half an hour following dissipation of the embolus. ${ }^{18}$ The model of focal cercbral ischacmia utilized in the present study consisted of major vessel occlusion for six hours without reperfusion and represents a much more severe ischaemic insult. With cerebral air embolism, the blood-brain barrier remains intact but intracranial pressure (ICP) is often elevated. ${ }^{3,18}$ With vessel occlusion there is early disruption of the blood-brain barrier but ICP often only rises many hours later. ${ }^{19} \mathrm{~A}$ bolus of lidocaine has been shown to reduce ICP and it may have been this effect rather than any metabolic benefit that produced the beneficial results in Evans' study. ${ }^{3,20}$ In addition, we observed that lidocaine infusion caused a transient reduction in the amplitude of the cortical peak. This is probably a reflection of the central sedative effects of lidocaine. This was not taken into consideration by Evans' group and all their amplitude changes were expressed as percentages of baseline values following lidocaine administration. This would tend to overestimate the percentage recovery as the effect of lidocaine alone on SEP wore off. They did not report the influence of lidocaine on SEP in their study. Applying their method of analysis, we also found a grealer recovery of amplitude in the lidocaine-treated animals (Table III). Our results are therefore consistent with their reported findings.

If Jidocaine does indeed have the ability to protect neurons from ischaemia, it is appropriate to speculate on why lidocaine failed to provide sustained benefit in the present investigation. As alluded to above, the ischaemia produced by six hours of MCA occlusion may have been too severe and sustained for a single bolus of lidocaine to protect. An infarct evolves over many hours. For lidocaine to influence infarct size, it probably must be present in the ischaemic area for the major part of this process. Because collateral blood flow allows some perfusion through the ischaemic area, the bulk of the drug initially trapped may have been washed out. Continuation of the drug infusion may therefore be beneficial.

If these results are verified by further studies in models of focal ischaemia, then this clinically relevant dose of lidocaine may prove useful during surgical procedures that render patients at risk for developing focal cerebral ischaemia. Examples of this are carotid endarterectomy and temporary clipping of an aneurysm's feeding vessel during obliteration of cerebral aneurysms. Although tempting, it would be inappropriate to extrapolate these results to global complete ischaemia such as cerebral ischaemia during cardiac arrest because there are substantial differences in the pathophysiology. ${ }^{21}$ Indeed, a recent study of lidocaine in a model of complete global ischaemia was unable to show a benetit. ${ }^{22}$

We conclude from this study that a single bolus of lidocaine, in this model of focal cerebral ischaemia, produces a transient preservation of the SEP. This effect was not sufficiently sustained to alter the extent or severity of the histological lesion. We believe that a continuous infusion of lidocaine warrants further investigation in models of temporary focal cerebral ischaemia.

\section{References}

1 Astrup J, Skovsted $P$, Gjerris $F$ et al. Increase in extracellular potassium in the brain during circulatory arrest: cffects of hypothermia, lidocaine, and thiopental.

Anesthesiology 1981; 55: 256-62.

2 Astrup J, Sorensen PM, Sorensen HR. Inhibition of cerebral oxygen and glucose consumption in the dog by hypothermia, pentobarbital, and lidocaine. Anesthesiology $1981 ; 55: 263-8$. 
3 Evans DE, Kobrine Al, LeGrys DC et al. Protective effect of lidocaine in acute cerebral ischemia induced by air embolism. J Nêurosurg 1984; 60: 257-63.

4 Shokunbi MT, Gelb AW. Peerless SJ et al. An evaluation of the effect of lidocaine in experimental focal cerebral ischemia. Stroke 1986; 17: 962-6.

5 Peerless $S J_{\text {, }}$ Ishikawa $R$, Hunter IG et al. Protective effect of fluosol-DA in acute cerebral ischemia. Stroke 1981: 12: 558-63.

6 Little JR, Sundt TM Jr, Kerr FWL. Neuronal alterations in developing cortical infarction. J Neurosurg 1974; 39 : $186-98$.

7 Astrup J, Rehncrona S, Siesjo BK. The increase in extracellular potassium concentration in the ischemic brain in relation to the prcischemic functional activity and cerebral metabolic rate. Brain Res 1980; 199: 161-74.

8 Fink BR. Paradoxical preservation of neural conduction by lidocaine. Anesthesiology 1982; 57; 161-71.

9 Astrup $J$. Energy-requiring cell functions in the ischemic brain. J Ncurosurg 1982; 56: 482-97.

10 Luostarinen V, Evers $H$, Lyytikainen MT et al. Antithrombotic effects of lidocaine and related compounds on laser-induced microvascular injury. Acta Anaesthesiol Scand 1981; 25: 9-11.

11 Lam AM. Do evoked potentials have any value in anaesthesia? Can J Anaesth 1987; 34: S32-6.

12 Astrup $J$, Symon L, Branston NM et al. Cortical evoked potenlial and extracellular $\mathrm{K}^{+}$and $\mathrm{H}^{+}$at critical level of brain ischemia. Stroke 1977; 8: 51-7.

13 Branston NM. Symon L, Crockard HA et al. Relationship between the cortical evoked potential and local cortical blood flow following acute middle cerebral artery occlusion in the baboon. Exp Neurol 1974; 45: 195-208.

14 Faden AI, Hallenbeck JM, Brown CQ. Treatment of experimental stroke: Comparison and thryotropin releasing hormone. Neurol 1982; 32: 1083-7.

15 Hargadine $J R_{1}$ Branston NM. Symon $L$. Central conduction time in primate brain ischemia - a study in baboons. Stroke 1980; 11: 637-42.

16 Lesnick JE, Michele JJ, Simeone FA et al. Alteration of somatosensory evoked potentials in response to global ischemia. J Neurosurg 1984; 60: 490-4.

17 Steinberg GK, Gelb AW, Lam AM et al. Correlation between somatosensory evoked potentials and neuronal ischemic changes following middle cerebral artery occlusion. Stroke 1986; 17: 1193-7.

18 Fritz $H_{1}$ Hossmann $K A$. Arterial air embolism in the cat brain. Stroke 1979; 10: 581-9.

19 Hossmann KA. The pathophysiology of ischemic brain swelling, in: Inaba Y, Klatzo 1, Spatz M. (Eds). Brain Edema. Springer-Verlag, 1985, pp 367-384.
20 Donegan MF, Bedford $R F$. Intravenously administered lidocaine prevents intracranial hypertension during endotracheal suctioning. Aresthesiology 1980; 52: 516-8.

21 Heuser $D$. Guggenberger $H$ : Ionic changes in brain ischaemia and alterations produced by drugs. $\mathrm{Br} J$ Anaesth 1985; 57: 23-33.

22 Warner DS, Godersky JC, Smith ML. Failure of preischemic lidocaine administration to ameliorate global ischemic brain damage in the rat. Anesthesiology 1988; 68: $73-8$.

Résumé

Afin de déterminer les effets d'un bolus intraveineter de $5 \mathrm{mg} \cdot \mathrm{kg}^{-1}$ de lidocaine sur la protection cérébrale. l'artère cérébraie moyenne gauche (MCA) a été obstruée par voie transorbitaire chez 19 chats. Dix chats ont reçu un bolus de lidocaine alors que neuf ont reçu un volume similaire de solution physio. logique immédiatement avant lobstruction de la MCA. Les potentiels évoqués somatosensorials (SEP) ont été enregistrës avant et après le bolus de lidocaïne et continuellement après locchision de la MCA. Sis heures après l'abstruction de rartère et sans reperfusion tes animaux on été sacrifiés et leur cerveau fixés pour histologie. Avant l'occlusion de MCA la lidocaine a provoqué une diminution statistiquement significative $(p<0.01)$ de l' amplitude des composantes majeures corticales de la SEP $(10 \pm 1.0 \mu \mathrm{V}$ vs $6.0 \pm 1.3 \mu \mathrm{V})$. La période de latence fut inchangee. Dars le groupe lidocaine les SEP ont persisté chez 40 potr cent innédiatement apres l'octusion aiors qu'ils ont disparu chez tous les animaux du groupe controle $(p<0.05)$. Une récupération graduelle est surveriue dans les deux groupes et il n' y avait aucune différence à la fin de l'expérience méme si les amplitudes étaient plus grandes dans le groupe lidocaïne. II n'y avait aucune différence statistiquement significative dans la taille histologique er la sévérité des infarc. tus entre les groupes. Si la taille de l'infarctus n' était pas réduite, la sauvegarde transitoire des SEP suggèrent que d' autres études avec la lidocaine en perfusion continue en présence d'une ischémie cérébrale focale temporaire seraient nécessaires. 